\title{
EFFECT OF ALTERED INTRATHORACIC PRESSURE ON RENAL HEMODYNAMICS, ELECTROLYTE EXCRETION AND WATER CLEARANCE *
}

\author{
By H. V. MURDAUGH, JR., $\dagger$ H. O. SIEKER AND F. MANFREDI $\ddagger$
}

(From the Department of Medicine, Duke University School of Medicine and the Veterans
Administration Hospital, Durham, N. C.)

(Submitted for publication September 15, 1958; accepted January 30, 1959)

Breathing against a continuous positive or negative pressure has been demonstrated to alter urine flow. Continuous positive pressure breathing is associated with a decrease in the rate of urine flow in dog (1) and man (2), whereas breathing against a constant negative pressure produces an increased rate of urine flow in the same species $(1,3)$. A decrease in urea clearance accompanies the antidiuresis of positive pressure breathing and suggests an altered rate of glomerular filtration (1). The diuresis of negative pressure breathing is not associated with marked changes in endogenous creatinine clearance or sodium and potassium excretion $(1,3)$.

These alterations in the rate of urine flow have been attributed to changes in distribution of blood within the chest (1). Positive pressure breathing is associated with a displacement of blood from the thorax, and breathing against a negative pressure results in an increase in the intrathoracic blood volume. Henry, Gauer and Reeves postulated that these changes in urine flow are brought about through stretch receptors in the wall of the atria and greater vessels of the thorax (4), and demonstrated that the response of the dog to negative pressure breathing could be prevented by chilling of the vagus (5). These reports suggested that such a pathway involves also a humoral substance of antidiuretic nature.

The study reported in this paper was designed to evaluate the role of renal hemodynamics and

\footnotetext{
* Supported in part from the Veterans Administration Clinical Investigator Program, in part from a United States Public Health Service Grant (A-1596) and in part from Life Insurance Medical Research Fund.

$\dagger$ Done during the tenure as a VA Clinical Investigator. Present address: Department of Medicine, University of Alabama Medical Center and Veterans Administration Hospital, Birmingham, Ala.

$\ddagger$ Research Fellow of the American Heart Association, 1958-59.
}

humoral factors in the production of the changes in rate of urine flow in response to pressure breathing with particular emphasis on the effects upon water clearance.

\section{METHODS}

Thirty-eight studies were performed on 12 normal volunteer medical students. Before the experiments, the subjects were trained to breathe comfortably against a continuous pressure and to void freely, emptying the bladder at 15 minute intervals. Proposed subjects who did not so adapt themselves were not used for the studies.

The rate of urine flow was observed for two to four hours under the circumstances of the particular experiment to insure a stable control rate. Fifteen minute urine collections were then obtained throughout three to six control periods, during 30 minutes of pressure breathing, and afterwards until the rate of urine flow returned to the control value.

Pressure breathing consisted of a continuous positive pressure in the range of 24 to $26 \mathrm{~mm}$. $\mathrm{Hg}$ or continuous negative pressure in the range of 18 to $22 \mathrm{~mm}$. $\mathrm{Hg}$. Continuous positive pressure was administered through a positive pressure demand valve system. Continuous negative pressure was obtained by breathing room air through a system which incorporated a large drum in which the negative pressure was maintained by a suction pump (3). The positive pressure breathing experiments were carried out with the subject in the seated position throughout the study (control, test, and recovery periods). The negative pressure breathing experiments were performed with the subject in the horizontal position during the entire study. Continuous positive pressure was administered during the states of water diuresis in nine subjects, alcohol diuresis in nine subjects, and mannitot osmotic diuresis in five subjects. Alcohol diuresis was accomplished by instituting a water diuresis and then giving $20 \mathrm{ml}$. absolute alcohol by mouth and adding $10 \mathrm{ml}$. absolute alcohol to the inulin infusion 30 to 45 minutes before the positive pressure breathing was started. Osmotic diuresis was obtained by administration of mannitol in the priming infusion and by a 15 per cent mannitol maintenance infusion. Negative pressure was used during the postabsorptive state in nine subjects who had received only one glass of water every two hours for the six hours prior to the study, and following vasopressin 
(Pitressin $\circledast$ ) or hypertonic salt administration in five subjects. Subjects were studied in both the morning and evening, thus avoiding the problem of diurnal variation.

Standard renal clearance techniques were used for the measurement of inulin, sodium para-aminohippurate $(\mathrm{PAH})$, sodium, potassium, osmolar and free water clearances. Prime and maintenance infusions of inulin and $\mathrm{PAH}$ were administered at a constant rate with an infusion pump and the administered load was calculated to obtain plasma concentrations of about $20 \mathrm{mg}$. per cent inulin and 1 to $2 \mathrm{mg}$. per cent PAH. Blood samples were obtained in heparinized syringes via an indwelling needle for the determination of plasma osmolality and plasma inulin, PAH, sodium and potassium concentrations. In some subjects urea clearances were also performed to
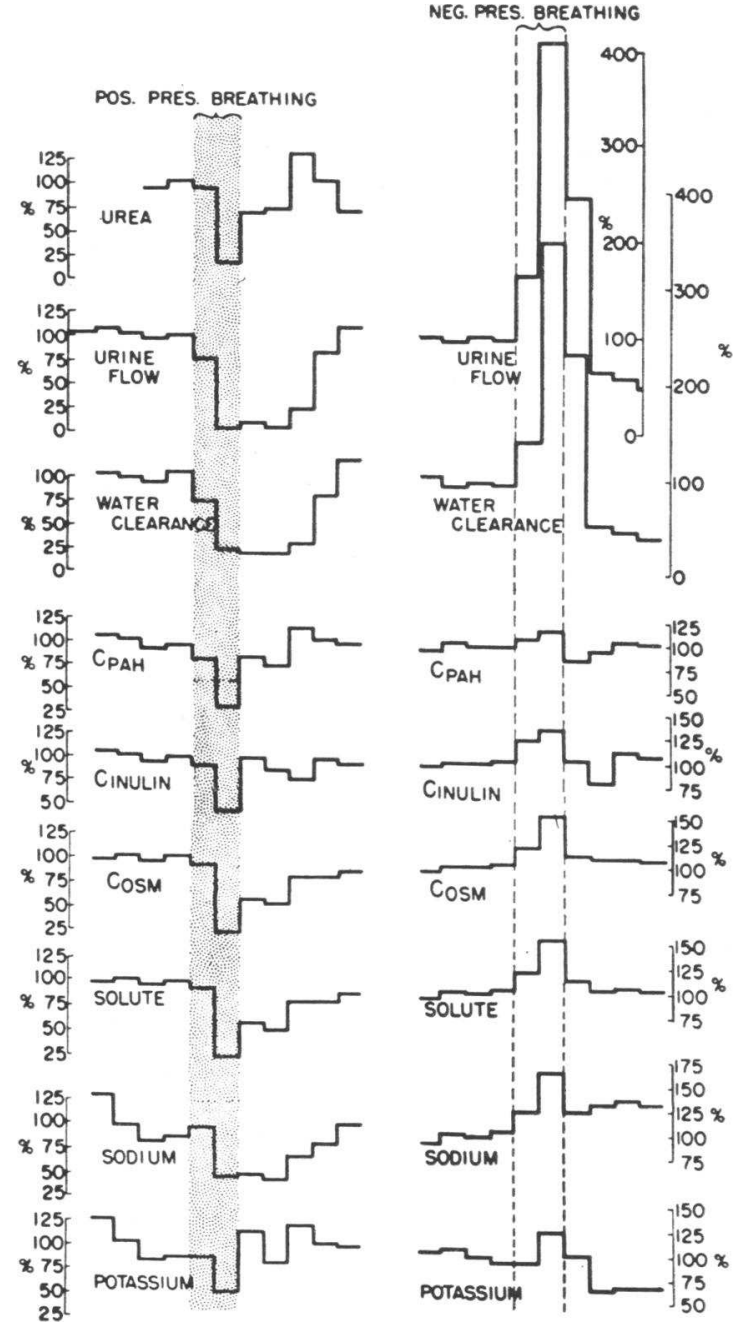

Fig. 1. Graphic Presentation of Data on a Single Subject Undergoing Continuous Positive and Continuous Negative Pressure Breathing

Percentile values are used to compare relative changes. For quantitative values refer to Subject D.H. in Tables I and III.

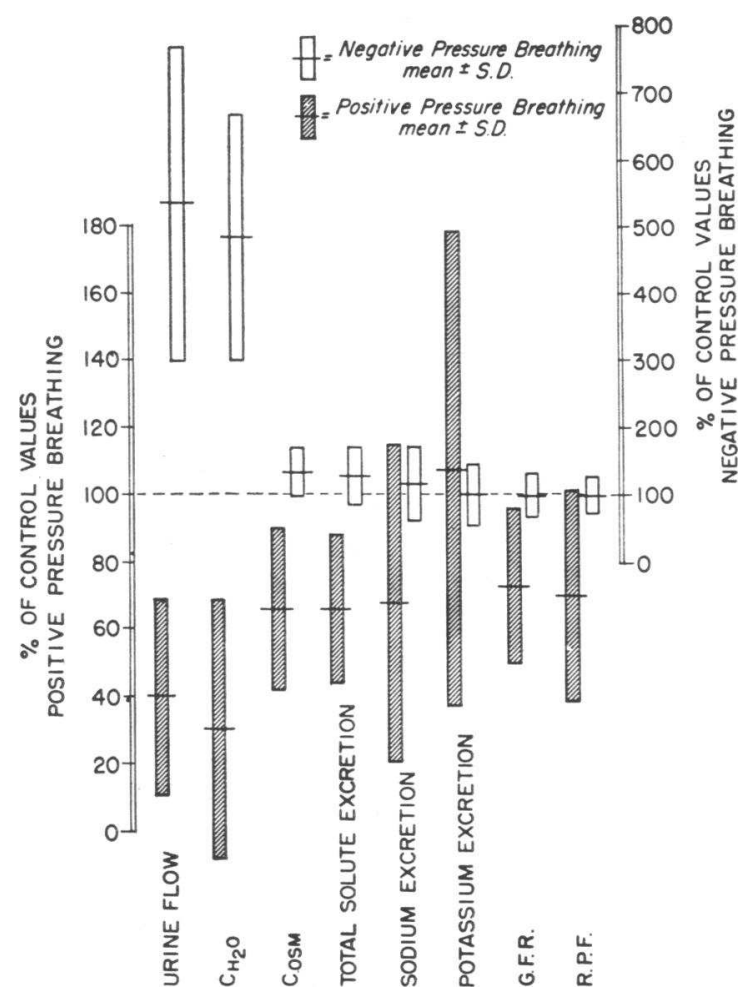

Fig. 2. Summary Diagram of All Studies Tabulated in Tables I and III, Giving Concise Comparison of the Effects of Continuous Positive and Continuous Negative Pressure Breathing

To obtain the percentile change for free water clearance $\left(\mathrm{C}_{\mathrm{H}_{2} \mathrm{O}}\right)$ during negative pressure breathing, the change in free water clearance was compared to the control rate of urine flow.

evaluate further the content of the urine solute. Inulin clearance was used as a measure of glomerular filtration rate (GFR). PAH clearance was divided by 0.9 to obtain renal plasma flow (RPF). Free water clearance was calculated from the osmolar clearance and the minute urine volume.

A plasma filtrate was made by the cadmium sulfate method of Fujita and Iwatake (6). Inulin was determined by the resorcinol method as modified by Schreiner (7). PAH determinations were carried out using the method of Selkurt (8) with the $\mathrm{N}$-napthyl ethylenediamine dihydrochloride recrystallized by hydrochloric acid as described by Bratton and Marshall (9). Osmolality measurements were performed using a Fiske Osmometer Model B. Sodium and potassium determinations were carried out using the internal standard flame photometer. Samples were analyzed for urea by the micro-diffusion method of Conway and O'Malley (10).

\section{RESULTS}

An example of the results obtained during both positive and negative pressure breathing experi- 


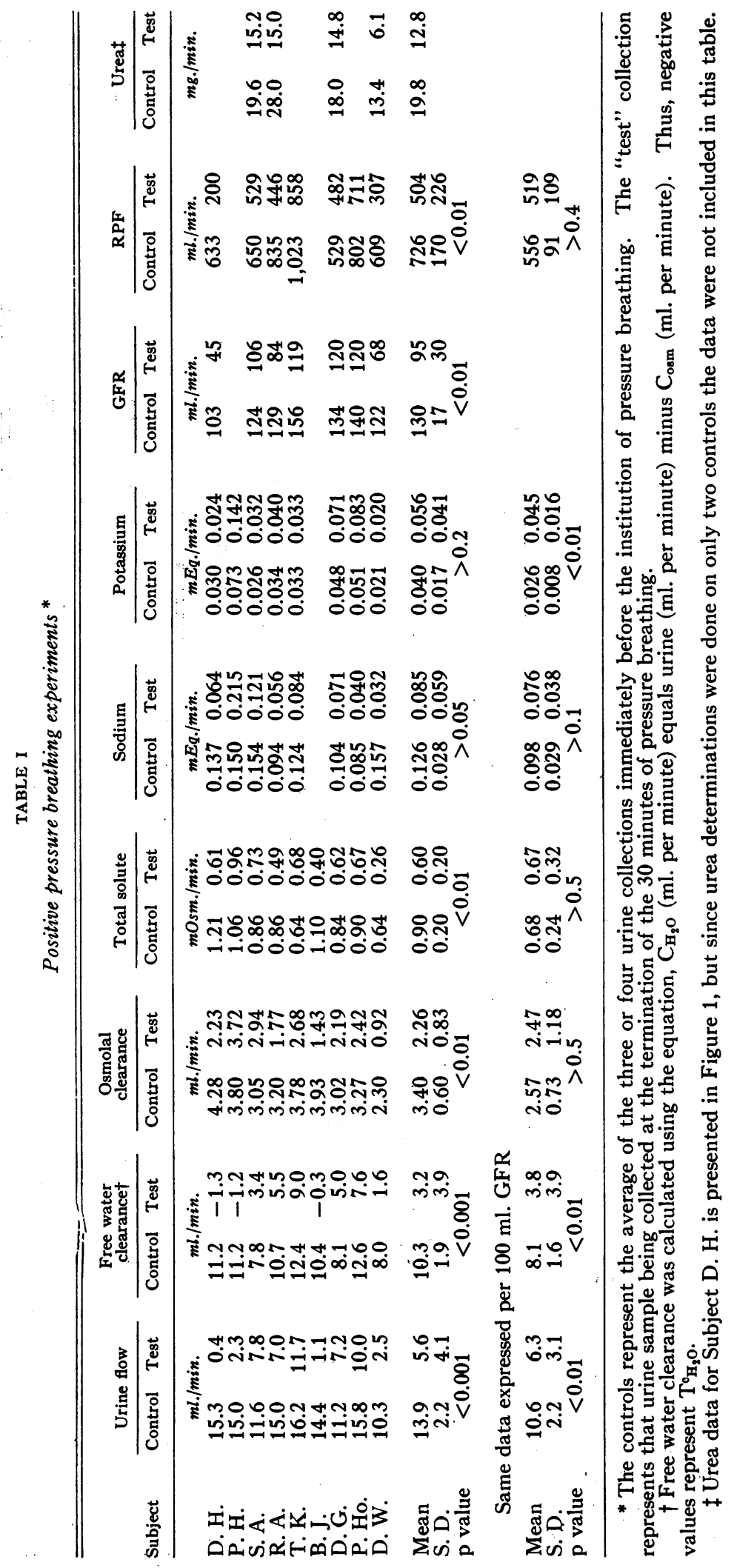


ments in the same subject is depicted in Figure 1. This subject had the most pronounced changes in GFR and RPF encountered during positive pressure breathing. In general, electrolyte excretion and total solute clearance paralleled the changes in the GFR. The changes in free water clearance, however, with resultant changes in the rate of urine flow were more pronounced and of longer duration than the changes in GFR.

\section{Positive pressure breathing}

Continuous positive pressure was administered to nine subjects during water diuresis with the demonstration of a prompt antidiuresis (Table I). The data for these nine subjects are presented in the summary diagram, Figure 2. For the group it can again be seen that solute excretion compares well with glomerular filtration rate. The most pronounced change occurred in the free water clearance with a resultant decrease in the rate of urine flow. This represented a true antidiuresis

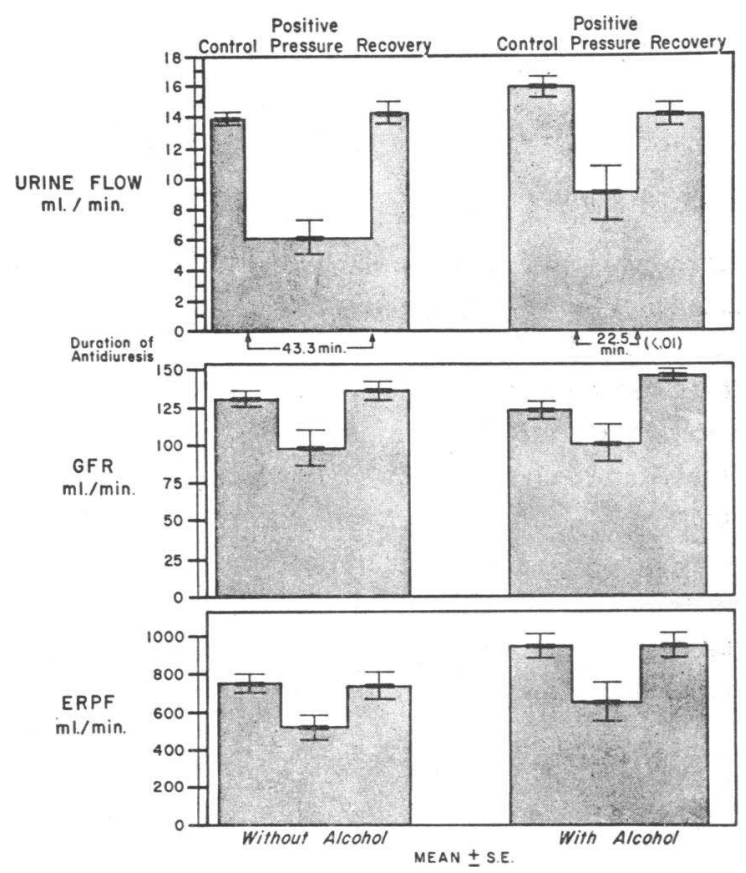

Fig. 3. Summary Diagram of Nine Subjects Comparing Response to 30 Minutes of Continuous Positive Pressure Breathing With and Without Alcohol

The duration and degree of change in the rate of urine flow are depicted. The $p$ value for the significance of the change in duration is noted.

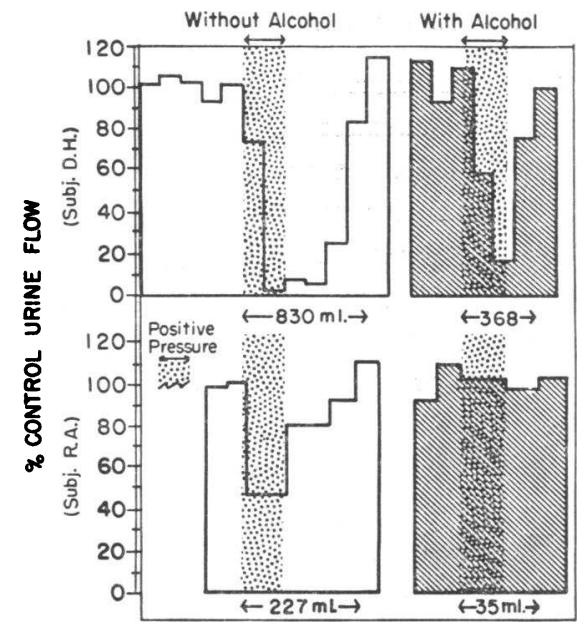

Fig. 4. Two Examples of the Effect of Alcohol Administration on the Antidiuresis of Positive Pressure Breathing to Show Decrease in Degree or Duration of ANTIDIURESis

The values between the arrows represent the difference between observed urine flow during the period depicted by the arrows and the urine flow that would have occurred during the same period if urine flow had remained at control rate.

and was accompanied by increase in osmolal urine to plasma $(\mathrm{U} / \mathrm{P})$ ratio.

As shown in Table I, there was a statistically significant decrease in the rate of urine flow, free water and osmolar clearance, sodium excretion, GFR and RPF. When the data were recalculated and expressed per $100 \mathrm{ml}$. GFR, only the rate of urine flow and the free water clearance were significantly decreased relative to GFR. The potassium excreted per $100 \mathrm{ml}$. GFR was significantly increased.

These subjects were studied again during alcohol diuresis and during mannitol osmotic diuresis. The administration of alcohol during water diuresis caused partial or complete inhibition of the antidiuretic effect of positive pressure breathing even though the change in GFR was similar to the group with water diuresis depicted in Table I (Figure 3). Figure 4 presents two examples of the inhibition by alcohol.

During osmotic diuresis with rates of urine flow as high as $16 \mathrm{ml}$. per minute there was no antidiuresis during or following positive pressure breathing, although there were decreases in GFR (Table II). 


\section{Negative pressure breathing}

Eight of nine normally hydrated subjects had a diuresis with dilution of the urine in response to continuous negative pressure breathing (Table III). The data for the eight subjects who had demonstrable diuresis are presented in the summary diagram, Figure 2. Although there were slight increases in solute excretion, it is apparent that the most pronounced change that occurred

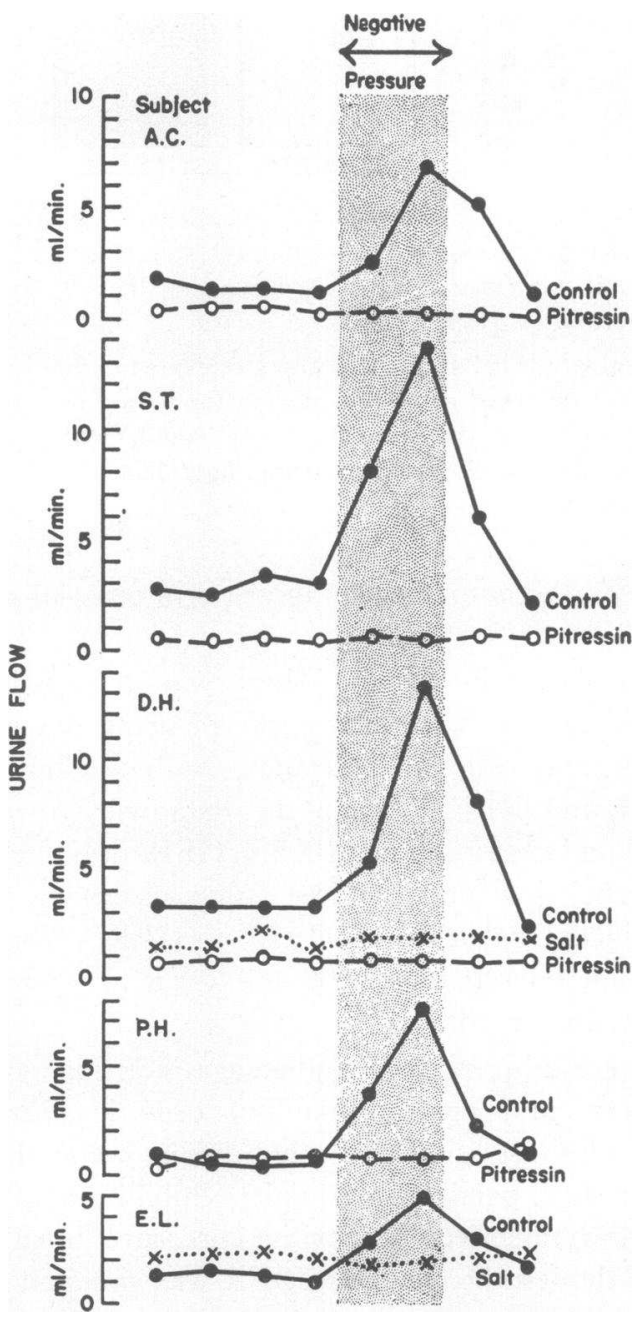

Fig. 5. The Plot of 15 Minute Urine Collections to Show the Effect of Negative Pressure Breathing on Urine Flow

The solid dots (O) represent the subject's normal response to negative pressure breathing, the open circles (O) represent response when given vasopressin before the institution of negative pressure breathing, and the $(X)$ 's represent the response to negative pressure breathing after infusion of hypertonic salt solution.
TABLE II

Positive pressure breathing during osmotic diuresis *

\begin{tabular}{|c|c|c|c|c|}
\hline \multirow[b]{2}{*}{ Subject } & \multicolumn{2}{|c|}{ Urine flow } & \multicolumn{2}{|c|}{ GFR } \\
\hline & Control & Test & Control & Test \\
\hline & \multicolumn{2}{|c|}{ ml. $/ \min$} & \multicolumn{2}{|c|}{ ml./min. } \\
\hline $\begin{array}{l}\text { D. H. } \\
\text { B. K. } \\
\text { V. M. } \\
\text { P. H. } \\
\text { B. J. }\end{array}$ & $\begin{array}{r}3.60 \\
3.42 \\
15.14 \\
5.30 \\
5.88\end{array}$ & $\begin{array}{r}3.93 \\
3.13 \\
15.10 \\
5.00 \\
4.30\end{array}$ & 112 & 58 \\
\hline
\end{tabular}

* Control values represent the average of three to six urine collections obtained prior to institution of positive pressure breathing. The "test" collection represents the urine being collected at the termination of 30 minutes of pressure breathing.

was an increase in free water clearance which was accompanied by a decrease in osmolal $\mathrm{U} / \mathrm{P}$ ratios to less than one.

The administration of vasopressin was found to prevent the diuresis in response to negative pressure breathing (Figure 5). Two subjects were given a continuous intravenous infusion of 2.5 per cent salt for three hours at $2 \mathrm{ml}$. per minute. There was noted an increase in plasma osmolality of 3 per cent, and negative pressure breathing did not alter the rate of urine flow (Figure 5).

\section{DISCUSSION}

The results of this study confirm earlier demonstrations of the alterations in urine flow that are associated with changes in intrathoracic pressure $(1-3,11-13)$. Although earlier reports suggested that water excretion was altered independent of electrolyte excretion and unrelated to changes in renal hemodynamics, these two factors were not completely evaluated. From the present study it is possible to conclude that alterations in electrolyte excretion and renal hemodynamics did occur during positive pressure breathing but are not of the magnitude or always in the direction of the changes in water clearance and rate of urine flow. On the other hand, electrolyte excretion and renal hemodynamics were not significantly changed with the diuresis of negative pressure breathing.

By controlling or taking into account such variables as fluid and solute intake, position, comfort and diurnal rhythm, there remained two factors to be considered in the production of an altered rate of urine flow. These were changes in antidiuretic 


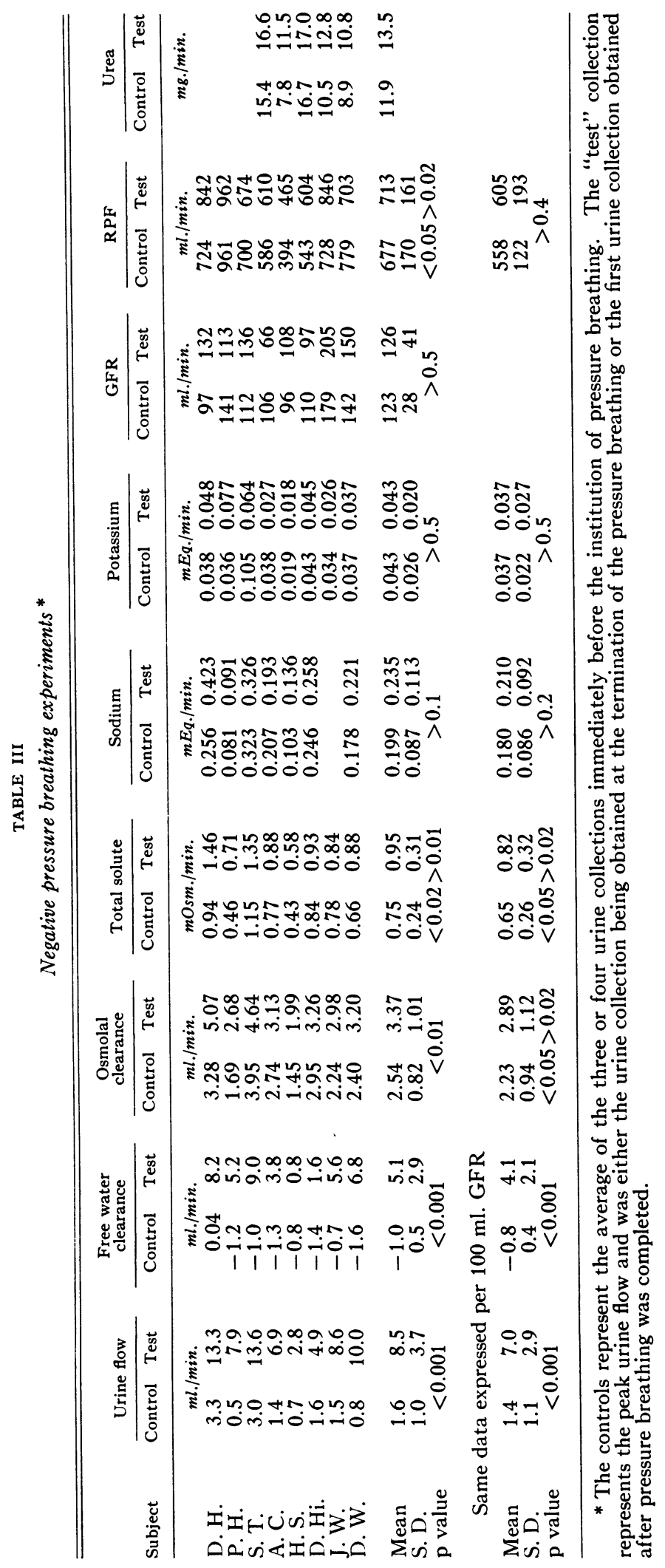


hormone activity with resultant changes in water clearance or alterations in renal hemodynamics.

With positive pressure breathing a decrease in the GFR and RPF occurred. This decrease was less in degree and duration than the change in water clearance and rate of urine flow, and it occurred during osmotic diuresis when no antidiuresis was noted in response to positive pressure breathing.

Alcohol is reported to inhibit the release of antidiuretic hormone $(\mathrm{ADH})$ from the posterior pituitary and thus block an antidiuretic response dependent upon $\mathrm{ADH}$ release (14). During alcohol-water diuresis partial or complete inhibition of the response to positive pressure breathing occurred even though the GFR was decreased. Van Dyke (15) has demonstrated that the human posterior pituitary contains about $15,000 \mathrm{mU}$ of $\mathrm{ADH}$, and that only 0.5 to $2.0 \mathrm{mU}$ is required to cause antidiuresis. This may be the explanation for the failure of alcohol to prevent completely the antidiuretic response to positive pressure breathing.

Since mannitol-induced osmotic diuresis is accompanied by pronounced ADH activity, it was felt that an added stimulus for the release of $\mathrm{ADH}$ would not cause a decrease in the rate of urine flow during prominent osmotic diuresis. It was realized that a decrease in GFR, by decreasing the solute load in the glomerular filtrate, might be associated with a decrease in the degree of osmotic diuresis. As it evolved, however, there did occur a decrease in GFR, but a decrease in the rate of urine flow did not occur.

When free voiding is used for urine collections in clearance procedures, the accuracy of the clearance for each individual urine collection period is less than that obtained if an indwelling catheter and terminal washouts are used. This error is, of course, accentuated with decreasing rate of urine flow. As a consequence, the decrease in GFR and other clearances during antidiuresis may have appeared more exaggerated than the changes which occurred. For this reason the data were recalculated and expressed per $100 \mathrm{ml}$. GFR, thus cancelling out the error of time and volume when comparing changes that occurred in the different clearance measurements. By this means it was apparent that the only significant decreases relative to GFR that occurred during positive pressure breathing were the rate of urine flow and the free water clearance. The presence of such differential changes and the increase in urine concentration demonstrate that the changes found were not a phenomenon of less accurate urine collections. On the other hand, the decreases in GFR which occurred during alcohol and osmotic diuresis when the rate of urine flow did not decrease demonstrates that a decrease in GFR in response to positive pressure breathing is real and not entirely a function of less complete urine collections.

From these considerations it is believed that the antidiuresis of positive pressure breathing is primarily related to ADH activity although a decrease in GFR may play a role.

It is of interest that the potassium excretion, expressed per $100 \mathrm{ml}$. GFR, increased during positive pressure breathing even though an antidiuresis occurred. The explanation for the increase in the potassium excretion is not clear.

It is apparent from the summary diagram of the data (Figure 2) that the diuresis of negative pressure breathing is not due to change in GFR or $\mathrm{RPF}$, but is due to an increase in the free water clearance with resultant increase in the rate of urine flow. Moreover, administration of vasopressin or an increase in plasma osmolality prior to negative pressure breathing inhibited the diuretic response. Therefore, it is concluded that a mechanism producing these effects must involve alteration of antidiuretic hormone activity.

Some of the effects of pressure breathing on the circulation have been studied but most of the investigation has been confined to anesthetized animals. In general, positive pressure breathing has been reported to decrease the central blood volume, cardiac output and arterial pressure. Negative pressure breathing should engorge the central blood reservoir, but reports on the effects on cardiac output and blood pressure have been conflicting. Recently, studies from this laboratory in conscious adults have demonstrated that positive pressure breathing decreases the central blood volume and cardiac output and that negative pressure breathing has the reverse effect (16). Neither positive nor negative pressure breathing altered plasma volume during the first half hour. It was concluded that within certain limits intrathoracic pressure and cyclic variation in that pressure are important in the distribution of blood volume. Pressure breathing, therefore, lends itself 
to experiments designed to investigate volume receptor areas.

The relationship between altered blood volume and changes in renal excretion of water and electrolytes have been recognized (17). However, there has been controversy regarding the site of a receptor area which can detect alterations in blood volume and initiate changes in rate of urine flow. Harrison and co-workers have reported a natriuresis and a moderate increase in urine flow with neck cuff inflation $(18,19)$. They have postulated that a volume receptor area in the brain is responsible for initiating these changes. Other investigators have been unable to confirm these experiments (20-23). Epstein, Post and McDowell (24) demonstrated a natriuresis with occlusion of $\mathrm{A}-\mathrm{V}$ fistulae and postulated that the volume receptor was in the arterial side of the vascular tree. Harrison and Epstein were both reporting manipulations that produced primarily a natriuresis. The response to pressure breathing, however, consists primarily of alterations in free water clearance and does not appear to be the same phenomenon.

It has been suggested in earlier reports that the intrathoracic portion of the cardiovascular system contains a volume receptor area $(1,3)$. Further study has demonstrated that the left atrium is one such receptor area $(4,5)$. The present observations suggest that volume receptor areas in the thorax are responsible primarily for altering water clearance by the kidney. Hyperventilation (21) and pulsatile stimuli to the lungs (25) have also been associated with a water diuresis.

\section{SUM MARY}

The effect of continuous pressure breathing upon renal function and water clearance has been studied. It was found that positive pressure breathing produces a decrease in urine flow resulting primarily from a decrease in free water clearance, with decrease in glomerular filtration rate (GFR) as a contributing factor. Negative pressure breathing is associated with an increase in free water clearance with resultant increase in the rate of urine flow without changes in GFR It is concluded that altered antidiuretic hormone $(\mathrm{ADH})$ activity is the primary mechanism by which continuous pressure breathing changes the rate of urine flow.

\section{ADDENDUM}

Since this manuscript was submitted, the following reference has appeared in print: Boyland, J. W., and Antkowiak, D. E. Mechanism of diuresis during negative pressure breathing. J. appl. Physiol. 1959, 14, 116.

\section{REFERENCES}

1. Gauer, O. H., Henry, J. P., Sieker, H. O., and Wendt, W. E. The effect of negative pressure breathing on urine flow. J. clin. Invest. 1954, 33, 287.

2. Drury, D. R., Henry, J. P., and Goodman, J. The effects of continuous pressure breathing on kidney function. J. clin. Invest. 1947, 26, 945.

3. Sieker, H. O., Gauer, O. H., and Henry, J. P. The effect of continuous negative pressure breathing on water and electrolyte excretion by the human kidney. J. clin. Invest. 1954, 33, 572.

4. Henry, J. P., Gauer, O. H., and Reeves, J. L. Evidence of the atrial location of receptors influencing urine flow. Circulat. Res. 1956, 4, 85.

5. Henry, J. P., and Pearce, J. W. The possible role of cardiac atrial stretch receptors in the induction of changes in urine flow. J. Physiol. (Lond.) 1956, 131, 572.

6. Fujita, A., and Iwatake, D. Bestimmung des echten Blutzuckers ohne Hefe. Biochem. Z. 1931, 242, 43.

7. Schreiner, G. E. Determination of inulin by means of resorcinol. Proc. Soc. exp. Biol. (N. Y.) 1950, 74, 117.

8. Selkurt, E. E. Measurement of renal blood flow. Meth. med. Res. 1949, 1, 196.

9. Bratton, A. C., and Marshall, E. K., Jr. A new coupling agent for sulfanilamide determination. J. biol. Chem. 1939, 128, 537.

10. Conway, E. J., and O'Malley, E. Microdiffusion methods. Ammonia and urea using buffered absorbents. Biochem. J. 1942, 36, 655.

11. Silvette, H. Some effects of low barometric pressures on kidney function in the white rat. Amer. J. Physiol. 1943, 140, 374.

12. Surtshin, A., Hoeltzenbein, J., and White, H. L. Some effects of negative pressure breathing on urine excretion. Amer. J. Physiol. 1955, 180, 612.

13. Knoefel, P. K., Handley, C. A., and Huggins, R. A. Renal functions during positive pressure respiration. Proc. Soc. exp. Biol. (N. Y.) 1953, 82, 430.

14. Eggleton, M. G. The diuretic action of alcohol in man. J. Physiol. (Lond.) 1942, 101, 172.

15. Van Dyke, H. B. The regulation of water excretion by the neurohypophysis. Bull. N. Y. Acad. Med. 1953, 29, 24.

16. Kilburn, K. H., Sieker, H. O., and Murdaugh, H. V., Jr. Hemodynamic effects of pressure breathing (abstract). Clin. Res. 1958, 6, 313.

17. Zuidema, G. D., Clarke, N. P., Reeves, J. L., Gauer, O. H., and Henry, J. P. Influence of moderate changes in blood volume on urine flow. Amer. J. Physiol. 1956, 186, 89. 
18. Lewis, J. M., Jr., Buie, R. M., Sevier, S. M., and Harrison, T. R. The effect of posture and of congestion of the head on sodium excretion in normal subjects. Circulation 1950, 2, 822.

19. Viar, W. N., Oliver, B. B., Eisenberg, S., Lombardo, T. A., Willis, K., and Harrison, T. R. The effect of posture and of compression of the neck on excretion of electrolytes and glomerular filtration: Further studies. Circulation 1951, 3, 105.

20. Fishman, R. A. The failure of intracranial pressurevolume change to influence renal function. J. clin. Invest. 1953, 32, 847.

21. Barbour, A., Bull, G. M., Evans, B. M., Jones, N. C. H., and Logothetopoulous, J. The effect of breathing 5 to 7 percent carbon dioxide on urine flow and mineral excretion. Clin. Sci. 1953, 12, 1.
22. Netravisesh, V. Effects of posture and of neck compression on outputs of water, sodium and creatinine. J. appl. Physiol. 1953, 5, 544.

23. Kelser, G. A., Izlar, H. L., Estes, E. H., and Warren, J. V. A comparison of the effects of posture and neck compression on the excretion of sodium. Clin. Res. Proc. 1955, 3, 136.

24. Epstein, F. H., Post, R. S., and McDowell, M. The effect of an arteriovenous fistula on renal hemodynamics and electrolyte excretion. J. clin. Invest. 1953, 32, 233.

25. Love, A. H. G., Roddie, R. A., Rosensweig, J., and Shanks, R. G. The effect of pressure changes in the respired air on the renal excretion of water and electrolytes. Clin. Sci. 1957, 16, 281. 